\title{
Native Chilean Berries Preservation and In Vitro Studies of a Polyphenol Highly Antioxidant Extract from Maqui as a Potential Agent against Inflammatory Diseases
}

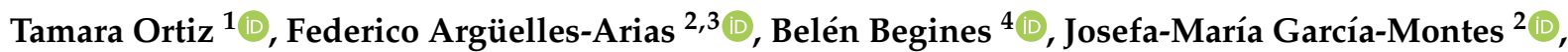 \\ Alejandra Pereira ${ }^{5}$, Montserrat Victoriano ${ }^{6}{ }^{\circledR}$, Victoria Vázquez-Román ${ }^{1}{ }^{\circledR}$, Juan Luis Pérez Bernal ${ }^{7}$, \\ Raquel M. Callejón ${ }^{8}$, Manuel De-Miguel ${ }^{1, * \mathbb{D}}$ and Ana Alcudia ${ }^{4, *(\mathbb{D})}$
}

check for updates

Citation: Ortiz, T.; Argüelles-Arias, F.; Begines, B.; García-Montes, J.-M.; Pereira, A.; Victoriano, M.;

Vázquez-Román, V.; Pérez Bernal, J.L. Callejón, R.M.; De-Miguel, M.; et al. Native Chilean Berries Preservation and In Vitro Studies of a Polyphenol Highly Antioxidant Extract from Maqui as a Potential Agent against Inflammatory Diseases. Antioxidants 2021, 10, 843. https://doi.org/ $10.3390 /$ antiox 10060843

Academic Editor: Ehab

A. Abourashed

Received: 22 March 2021

Accepted: 20 May 2021

Published: 25 May 2021

Publisher's Note: MDPI stays neutral with regard to jurisdictional claims in published maps and institutional affiliations.

Copyright: (c) 2021 by the authors. Licensee MDPI, Basel, Switzerland. This article is an open access article distributed under the terms and conditions of the Creative Commons Attribution (CC BY) license (https:/ / creativecommons.org/licenses/by/ $4.0 /)$.
1 Departamento de Citología e Histología Normal y Patológica, Universidad de Sevilla, Avda. Sánchez-Pizjuán s/n, 41009 Sevilla, Spain; tamara.ortiz.cerda@gmail.com (T.O.); mvazquez2@us.es (V.V.-R.)

2 Departamento de Medicina, Universidad de Sevilla, Avda. Sánchez-Pizjuán s/n, 41009 Sevilla, Spain; farguelles1@us.es (F.A.-A.); jfgarcia@us.es (J.-M.G.-M.)

3 Departamento de Gastroenterología, Hospital Universitario Virgen Macarena, c/Dr. Fedriani n ${ }^{\circ}$, 41009 Sevilla, Spain

4 Departamento de Química Orgánica y Farmacéutica, Universidad de Sevilla, c/Prof García González nº 2, 41012 Sevilla, Spain; bbegines@us.es

5 Departamento de Nutrición y Dietética, Escuela de Ciencias de la Salud, Universidad de Desarrollo Concepción Barrios Arana1735, Concepción 4070146, Chile; alejandra.pereira@udd.cl

6 Departamento de Nutricion y Dietetica, Facultad de Farmacia, Universidad de Concepción, Concepción, Chile. Barrio Universitario s/n, Concepción 4070146, Chile; mvictoriano@udec.cl

7 Departamento de Química Analítica, Universidad de Sevilla, c/Prof García González nº 2 , 41012 Sevilla, Spain; juanluis@us.es

8 Departamento de Nutrición y Bromatología, Toxicología y Medicina Legal, Universidad de Sevilla, c/Prof García González nº 2, 41012 Sevilla, Spain; rcallejon@us.es

* Correspondence: mmiguel@us.es (M.D.-M.); aalcudia@us.es (A.A.); Tel.: +34-955-421-025 (M.D.-M.); +34-954-556-740 (A.A.)

Abstract: The best conservation method for native Chilean berries has been investigated in combination with an implemented large-scale extract of maqui berry, rich in total polyphenols and anthocyanin to be tested in intestinal epithelial and immune cells. The methanolic extract was obtained from lyophilized and analyzed maqui berries using Folin-Ciocalteu to quantify the total polyphenol content, as well as 2,2-diphenyl-1-picrylhydrazyl (DPPH), ferric reducing antioxidant power (FRAP), and oxygen radical absorbance capacity (ORAC) to measure the antioxidant capacity. Determination of maqui's anthocyanins profile was performed by ultra-high-performance liquid chromatography (UHPLC-MS/MS). Viability, cytotoxicity, and percent oxidation in epithelial colon cells (HT-29) and macrophages cells (RAW 264.7) were evaluated. In conclusion, preservation studies confirmed that the maqui properties and composition in fresh or frozen conditions are preserved and a more efficient and convenient extraction methodology was achieved. In vitro studies of epithelial cells have shown that this extract has a powerful antioxidant strength exhibiting a dose-dependent behavior. When lipopolysaccharide (LPS)-macrophages were activated, noncytotoxic effects were observed, and a relationship between oxidative stress and inflammation response was demonstrated. The maqui extract along with 5-aminosalicylic acid (5-ASA) have a synergistic effect. All of the compiled data pointed out to the use of this extract as a potential nutraceutical agent with physiological benefits for the treatment of inflammatory bowel disease (IBD).

Keywords: maqui berry extract; preservation methods; antioxidant activity; polyphenols and anthocyanins content; oxidative stress; inflammation; RAW 264.7 cells; HT-29 cells; inflammatory bowel disease 


\section{Introduction}

Inflammatory bowel disease (IBD) includes a group of diverse inflammatory diseases with chronic relapsing disorders and uncontrolled inflammation of the gastrointestinal tract such as ulcerative colitis (UC) or Crohn's disease (CD). Additionally, the prevalence and incidence of IBD in adults and children has increased worldwide during the last decades, mainly in Westernized countries of Europe and North America, and more recently in industrialized countries. In Europe, more than 2.2 million patients with IBD have been reported and it is increasing more and more in the last decade [1,2]. Unfortunately, no clear or definitive evidence has been found related to the pathogenesis' origin mainly due to its complexity. Urban populations, lifestyle, stress, smoking, and non-healthy diets based on high intakes of fats and poor intakes in vegetables or fruits are associated with alteration of intestinal microbiota that increase the risk of IBD in genetically susceptible individuals $[3,4]$. On the other hand, physiological concentrations of reactive oxygen species (ROS) are essential for cell survival and several physiological processes, including protein phosphorylation, activation of transcription factors, cell differentiation, apoptosis and cell immunity, etc. [5]. The effect of oxidative stress (OS) may have an impact on the pathophysiology of numerous chronic diseases, by reactions with the fatty acids of membranes, proteins, and DNA damage [6]. At the level of the gastrointestinal tract, OS can result in harmful effects such as stimulation of leukocytes infiltration, epithelial damage, mucus content depletion, and rupture of colonic barriers, along with inflammatory mediator release including inflammatory cytokines and arachidonic acid metabolites, as well as ROS, leading to oxidative damage and contributing to the development of IBD [7].

In this context, nutraceuticals or functional foods have gained popularity worldwide due to their high-value bioactive compounds [8]. Fruits and especially edible berries are rich sources of a wide variety of antioxidant phenols and include a high content of polyphenols and flavonoids [9]. In general, berries exhibit antioxidant and anti-inflammatory properties, decreasing OS and increasing intestinal protection, and can promote the prolongation of the remission phase and the duration/intensity of acute phases [10,11]. Among the most interesting berries for their high antioxidant capacity (AC) are the maqui and murta [12]. Aristotelia chilensis (Molina) Stuntz or maqui, endemic from Chile and widely consumed by its inhabitants, is an indigenous plant used as medicine. It contains an exceptional contribution both in concentration and in a variety of polyphenols (anthocyanins and non-anthocyanins) [13], with an extraordinary antioxidant power and a remarkable anti-inflammatory effect [14]. Moreover, Ugni molinae, known as murtilla or murta, is a wild berry native plant occurring in the lowlands of the southern mountains of Chile [15] and it is an interesting berry to be compared to maqui. A study reported by Speisky et al. [16] showed that the AC of maqui is still much higher than other cultivated berries and natural products. In general, berries are commonly consumed not only in fresh and frozen forms but also as processed tablets or pills [9]. For this reason, several studies have evaluated the effects and impact of different methods of food preservation on the maintenance of bioactive compounds and antioxidant activity. For example, the thermal effect caused by the different sterilization methods (thermal, microwave, and ultrasonic processing) on canned berries decreases the antioxidant activity and total content of anthocyanins and phenolics, whereas a low temperature storage better preserves the bioactive compounds and antioxidant activity $[17,18]$. Once the fruit has been preserved to retain its best characteristics as an antioxidant, an extraction to separate the desired natural products from the raw materials is needed. In this sense, and according to the highest antioxidant power of the maqui berry, various ways of production of maqui extracts have been described aiming to preserve not only the content of bioactive compounds but also the highest antioxidant activity $[19,20]$. Among them, the methanolic extract method has shown to preserve the highest AC, measured by oxygen radical absorbance capacity (ORAC), the radical scavenging activity using 2,2-diphenyl-1-picrylhydrazyl (DPPH) [21], ferric reducing antioxidant power (FRAP) [22], and total polyphenols content (TPC), measured by the Folin-Ciocalteu method [21]. In total, three groups of polyphenolic compounds have been described: Anthocyanins (del- 
phinidin 3-O-sambubioside-5-O-glucoside, delphinidin 3,5-O-diglucoside, cyaniding 3-Osambubioside-5-O-glucoside, cyaniding 3,5-O-diglucoside, delphinidin 3-O-sambubioside, delphinidin 3-O-glucoside, cyaniding 3-O-glucoside, and cyaniding 3-O-sambubioside), flavonols (quercetin, myricetin, kaemphenol, and its derivates), and phenolic acids (gallic acid). Recent studies have shown that the most abundant compounds are delphinidin and cyanidin derivatives that confer possible health benefits such as anti-inflammatory and antioxidant effects $[23,24]$. The characterization of the anthocyanin profile in maqui fruit has been performed using high-performance liquid chromatography-diode array detection and mass spectroscopy (HPLC-DAD-MS) [25], with delphinidin-3-sambubioside-5-glucoside as the majority delphinidin derivative, accounting for $34 \%$ of the total anthocyanidin level in maqui $[26,27]$.

Interestingly, different authors have described a beneficial biological effect of maqui extract in cellular culture. For example, pre-incubation of fibroblast and Caco-2 cells with anthocyanin rich maqui berry extract has shown a protective effect against OS along with a high capacity to inhibit human low-density lipoprotein (LDL) oxidation [28]. Additionally, the maqui extract exhibits an important anti-inflammatory effect in RAW 264.7 macrophages cells [29] by inhibition of gene expression of $i N O S, C O X-2, T N F-\alpha, I L-6$, and IL-10 $[24,30]$.

The aim of the present study is to estimate the TPC and evaluate the AC of two native Chilean berries in different types of preservation methods: Fresh, refrigerated, and frozen. Furthermore, the correlations between the phenolic content and antioxidative activity were evaluated. To obtain a large-scale amount of maqui berry extract, richer in polyphenols content and with a more important antioxidant capacity than murta was an objective, together with exploring the curative benefits as a potential agent in the treatment of IBD. The maqui extract was evaluated in vitro, testing its viability, cytotoxicity, and antioxidant properties in colonic epithelial cell lines (HT-29) and macrophages (RAW 264.7).

\section{Materials and Methods}

\subsection{Reagents and Apparatus}

Chemical reagents and solvents for the extraction $(\mathrm{MeOH}, \mathrm{HCl})$, total polyphenols content analysis (Folin-Ciocalteu reagent, gallic acid, and sodium carbonate), DPPH assay, 2,2'-azobis(2-amidinopropane) dihydrochloride (AAPH) and reagents for FRAP analysis (sodium acetate trihydrate/glacial acetic acid, Trolox (6-hydroxy-2,5,7,8-tetramethylchroman2-carboxylic acid), TPTZ (2,4,6-tripyridyl-s-triazine), and iron(III) sulphate $\left(\mathrm{Fe}_{2}\left(\mathrm{SO}_{4}\right)_{3} \cdot 7 \mathrm{H}_{2} \mathrm{O}\right)$ ) were purchased from Sigma-Aldrich (Saint Louis, MO, USA) and used without further purification. Determination of maqui's anthocyanins was performed by ultra-highperformance liquid chromatography (UHPLC-MS/MS) coupled to a hybrid quadrupoleorbitrap mass spectrometry system (Qexactive, Thermo Fisher, Waltham, MA, USA) with electrospray ionization (HESI-II). Separation was carried out using an Acquity UPLC BEH C18 (2.1 × $100 \mathrm{~mm}$ i.d., 1.7 um particle size) column (Waters, Milford, MA, United States) set to $40{ }^{\circ} \mathrm{C}$. Celite ${ }^{\circledR}$ Hyflo Supercel and membrane filter (filter paper, MFS) for filtration were from Merk (Darmstadt, Germany) and Biorad (California, USA), respectively. Fetal bovine serum (FBS), trypsin/ethylenediaminetetraacetic acid (EDTA), penicillin/streptomycin (P/S), McCoy's 5a, and dulbecco's modified eagle medium (DMEM) high glucose culture medium were purchased from Biowest (Nuaillé, France). N-acetylL-cysteine 5 (NAC), 5-aminosalicylic acid (5-ASA), and lipopolysaccharide (LPS) were obtained from Sigma-Aldrich (Saint Louis, MO, USA). The Alamar Blue ${ }^{\circledR}$ cell viability reagent and $2^{\prime}, 7^{\prime}$-dichlorofluorescin diacetate (DCFDA) were purchased from Thermo Fisher Scientific (Waltham, MA, USA). The ultrasound, rotary evaporator with controlled heating, lyophilizer, optical microscope, and microplate reader were purchased from Hielscher Ultrasound Technology (UP400S, Wanaque, NJ, USA), Telstar Cryodos (Josep Tapiolas, Terrassa, Spain), Leica (Wetzlar, Germany) and Tecan (Männedorf, canton of Zürich, Switzerland) companies, respectively. 


\subsection{Plant Material and Preservation Methods}

Wild maqui and murta berries have been collected from areas near the Andes Mountains: Bio-Bio and Araucanía Region, Chile. The fruits were separated in three groups for analytical procedures: (a) Refrigeration at $4{ }^{\circ} \mathrm{C}$ for 1 week, (b) freezing at $-18{ }^{\circ} \mathrm{C}$ for 1 month, and (c) fresh fruits. The fresh samples were analyzed immediately and treated according to the procedure described by Rubilar et al. [12]. All of the berries were dried at $35^{\circ} \mathrm{C}$ at an equative weight. Subsequently, grinding and sifting steps were conducted. The samples were macerated with ethanol $(50 \% v / v$ in water, $20 \% w / v$ at room temperature for $2 \mathrm{~h}$ ). The extracts were filtered through a membrane filter, centrifuged at 2600 relative centrifugal force $(\mathrm{RCF})$ for $30 \mathrm{~min}$ at $20^{\circ} \mathrm{C}$, and lyophilized.

\subsection{Preparation of Polyphenolic Maqui Extract (Ach)}

For the large-scale extract, lyophilized wild maqui was used including seeds, skin, and pulp obtained from a powder wild harvested in Patagonia, marketed by "ISLA NATURA DE CHILE ${ }^{\circledR \prime \prime}$ (Los Lagos, Chile). In order to quantitatively extract the raw maqui polyphenols, the extraction procedure was carried out using acidic methanol $\left(\mathrm{MeOH} / \mathrm{H}^{+}\right)$following a method published by Genskowsky et al. [20], although some modifications were implemented (Figure 1). The entire procedure was performed in darkness and at room temperature as described by Miranda Rottmann et al. [28] to avoid decomposition processes. A suspension of lyophilized maqui powder $(50 \mathrm{~g})$ in $0.1 \% \mathrm{HCl}$ in $\mathrm{MeOH}(250 \mathrm{~mL})$ was stirred for $15 \mathrm{~min}$. Afterwards, the mixture was sonicated with an ultrasound device at maximum power for $2 \mathrm{~min}$. The sample was centrifuged at $2600 \mathrm{RCF}$ for $10 \mathrm{~min}$ and allowed to precipitate for $5 \mathrm{~min}$. Finally, the supernatant was recovered in an Erlenmeyer (Thermo Fisher Scientific, Waltham, MA, USA). The previous process was repeated 5 times identically. Once all the supernatants were compiled, the solution was placed in a rotary evaporator for $2-3 \mathrm{~h}$ at $35^{\circ} \mathrm{C}$, in order to evaporate the organic solvent and concentrate the extract. The extract was resuspended in pure water, centrifuged at $2600 \mathrm{RCF}$ for $4 \mathrm{~min}$, and the supernatant recovered. Then, the filtering process was performed using a vacuum, with a short pad of celite, then passed through filter paper \#1 (porosity 100-150 MM) and then \#3 (porosity 40-100 MM). Finally, the lyophilization process was carried out for $24 \mathrm{~h}$ to prevent enzymatic and chemical changes, protein denaturation, loss of aromas, and easily oxidizable components, to get a highly hydroscopic powder that was stored at $-20^{\circ} \mathrm{C}$.

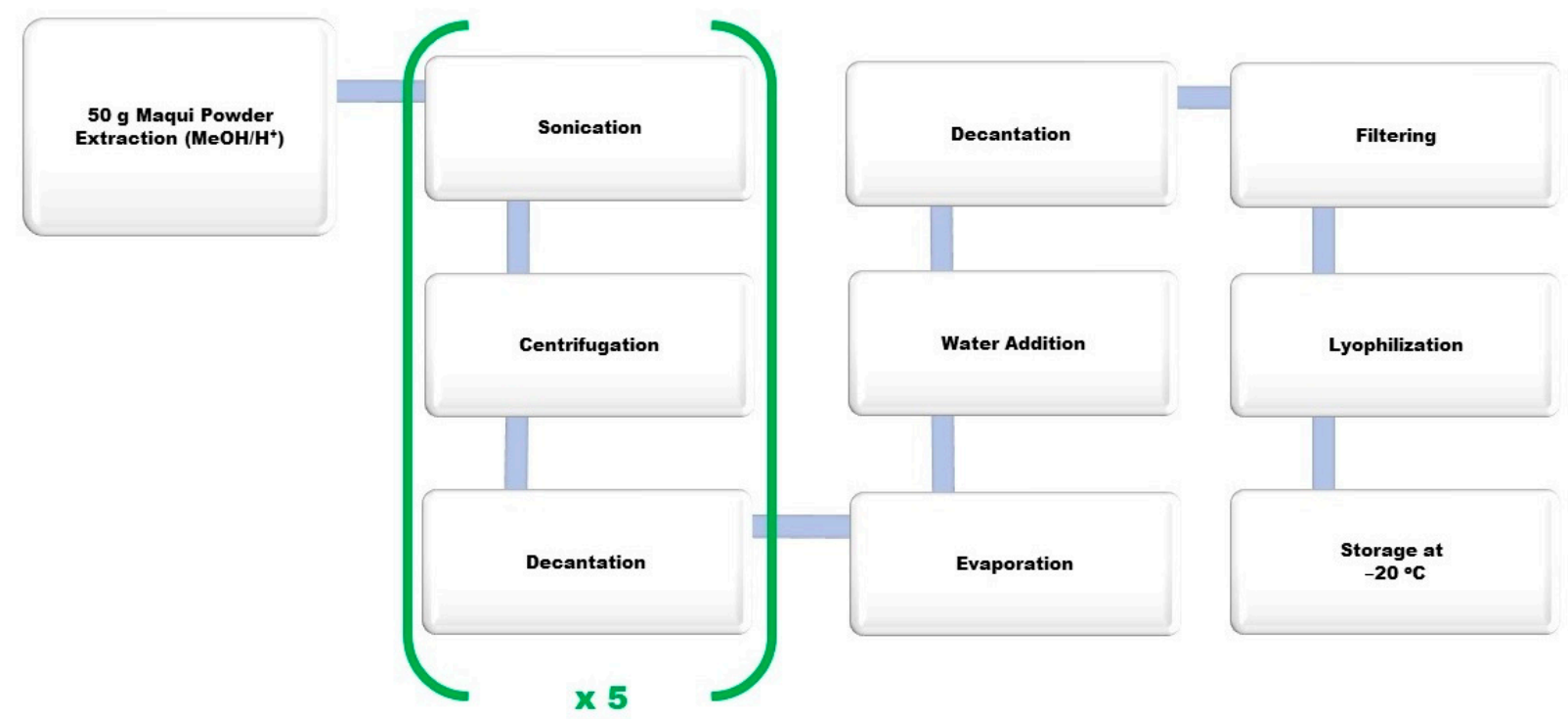

Figure 1. Conceptual scheme of maqui extraction procedure for $50 \mathrm{~g}$. 


\subsection{The 2,2-Diphenyl-1-Picrylhydrazyl (DPPH) Free Radical Scavenging Activity Assay}

This assay is based on the decoloration of DPPH free radical solution due to the free radical scavenging effect of antioxidants. The radical scavenging activity was estimated by the method described by Brand Williams [31] with minor modifications: $800 \mu \mathrm{L}$ of extracts were mixed with $3.9 \mathrm{~mL}$ of methanolic solution containing $0.1 \mathrm{mmol}$ of radical DPPH. After $30 \mathrm{~min}$ of incubation in a dark chamber, absorbance was measured at $520 \mathrm{~nm}$. Results were expressed as the half maximal effective concentration EC50, defined as the concentration that causes a 50\% decrease in the initial DPPH concentration.

\subsection{Oxygen Radical Absorbance Capacity (ORAC) Assay}

The ORAC assay was performed according to the method described by Zheng and Wang [32]. This assay estimates the ability of antioxidant components to inhibit the decline of oxidative degradation of a fluorescent molecule $((R)$-phycoerythrin $(R-P E))$ induced by peroxyl radical generator AAPH. The assay was prepared by mixing $1.7 \mathrm{~mL}$ of phosphate buffer (pH 7.0), $100 \mu \mathrm{L}$ of $R$-PE (3.4 mg/L), $100 \mu \mathrm{L}$ of AAPH, and $100 \mu \mathrm{L}$ of each sample. Samples without radicals were preincubated at $37^{\circ} \mathrm{C}$ for $15 \mathrm{~min}$. Fluorescence was recorded every $5 \mathrm{~min}$ at $540 \mathrm{~nm}$ excitation until the last fluorescence reading decreased $5 \%$ from the first reading. The antioxidant activity was expressed as $\mathrm{mg}$ of Trolox equivalents (TE) per gram of dry mass (DM) of plant material used for extraction (mg TE/g DM), according to the standard curve previously prepared.

\subsection{Ferric Reducing Antioxidant Power Estimation (FRAP) Assay}

AC was determined by FRAP, according to Benzie and Strain [33] with some modifications. The FRAP assay is a simple, reproducible, rapid, and inexpensive method that measures the reductive ability of antiradical species and is evaluated by the transformation of ferric ion $\mathrm{Fe}^{3+}$ to ferrous $\mathrm{Fe}^{2+}$. This last one gives a blue complex by the reaction with TPTZ and is compared against the AC of Trolox as a measure of total antioxidant capacity. The FRAP reagent was prepared by mixing in this order, acetate buffer $(0.3 \mathrm{M}, \mathrm{pH} 3.6)$, $10 \mathrm{mM}$ TPTZ in $40 \mathrm{mM} \mathrm{HCl}$, and $20 \mathrm{mM} \mathrm{Fe} 2\left(\mathrm{SO}_{4}\right)_{3} \cdot 7 \mathrm{H}_{2} \mathrm{O}$. A fresh acetate buffer was previously prepared by dissolving $3.1 \mathrm{~g}$ of sodium acetate trihydrate and $16 \mathrm{~mL}$ of acetic acid in $1 \mathrm{~L}$ of distilled water. The ready-to-use FRAP reagent was also freshly prepared by mixing the acetate buffer, TPTZ, and $\mathrm{Fe}_{2}\left(\mathrm{SO}_{4}\right)_{3} \cdot 7 \mathrm{H}_{2} \mathrm{O}$ in 10:1:1 proportion. Two solutions at different concentrations of extract were made from a stock solution of $1.28 \mathrm{mg} / \mathrm{mL}$ to determine its antioxidant activity. In summary, $50 \mu \mathrm{L}$ of extracts were added to the diluted FRAP reagent in $\mathrm{MeOH}$ ( $1 \mathrm{~mL}$ FRAP reagent mixed with $2 \mathrm{~mL} \mathrm{MeOH})$. The measure of absorbance was recorded at $593 \mathrm{~nm}$ after $30 \mathrm{~min}$ in darkness at room temperature against a blank (FRAP diluted reagent previously prepared without the extract). The standard curve was prepared using different concentrations of Trolox and the results were expressed as $\mu \mathrm{mol} \mathrm{TE} / 100 \mathrm{~g}$.

\subsection{Determination of Total Polyphenols Content (TPC)}

The Folin-Ciocalteu method is a type of assay based on an electron transfer mechanism. To provide basic conditions, $\mathrm{Na}_{2} \mathrm{CO}_{3}$ is used in the solution to dissociate phenolic protons that yield phenolate anions. Phenolate anions can reduce the Folin-Ciocalteu reagent through the reduction of $\mathrm{Mo}^{6+}$ to $\mathrm{Mo}^{5+}$ that results in a blue chromophore constituted by a phosphotungstic-phosphomolybdenum complex that can be measured spectrophotometrically [34]. The following methodology described by Slinkard and Singleton [35] was used for measurement. Then, $20 \mu \mathrm{L}$ of the sample, $1580 \mu \mathrm{L}$ distilled water, $100 \mu \mathrm{L}$ Folin-Ciocalteu reagent, and $300 \mu \mathrm{L} \mathrm{Na}_{2} \mathrm{CO}_{3}(200 \mathrm{~g} / \mathrm{L})$ were added to a glass tube. These solutions were mixed and incubated at $40{ }^{\circ} \mathrm{C}$ for $30 \mathrm{~min}$ in a water bath. Absorbance was measured at $740 \mathrm{~nm}$ against a blank solution. Gallic acid was used as a standard. All results were expressed as milligrams of gallic acid equivalent (GAE) per gram of dry matter (DM). 


\subsection{Determination of Anthocyanin Profile by UHPLC-HRMS/MS}

Determination of maqui's anthocyanins was performed with a Thermo Scientific Liquid Chromatography system consisting of a binary UHPLC Dionex Ultimate 3000 RS connected to a quadrupole-orbitrap Qexactive hybrid mass spectrometer (Thermo Fisher Scientific, Waltham, MA, USA) with a heated electrospray ionization probe (HESI-II). The Xcalibur software (Thermo Fisher Scientific, Waltham, MA, USA) was used for instrument control and data acquisition. Separation was carried out using an Acquity ethylene bridged hybrid $(\mathrm{BEH}) \mathrm{C} 18(2.1 \times 100 \mathrm{~mm}, 1.7 \mu \mathrm{m}$ particle size) column (Waters, Milford, MA, USA) set to $35{ }^{\circ} \mathrm{C}$ at a flow rate of $0.4 \mathrm{~mL} / \mathrm{min}$. A binary gradient consisting of (A) water $/$ formic acid 95:5 $(v / v)$ and $(B)$ acetonitrile/formic acid 95:5 $(v / v)$ was used with the following elution profile: $0-2 \mathrm{~min} 5 \% \mathrm{~B}, 2-12 \mathrm{~min}$ from $5 \%$ to $100 \% \mathrm{~B}, 12-13 \mathrm{~min} 100 \% \mathrm{~B}$, and $13-15 \mathrm{~min}$ $5 \%$ B. The injected volume was $5 \mu \mathrm{L}$. The lyophilized extract was dissolved in $1 \mathrm{~mL}$ of mobile phase A and microfiltered with a $0.2 \mu \mathrm{m}$ nylon filter. A Data Dependent Acquisition method (TOP5) was used in a positive mode at a resolution of 70,000 and 17,500 at $\mathrm{m} / \mathrm{z}$ 200 full-width half-maximum (FWHM) for Full Scan and Product Ion Scan, respectively. HESI source parameters were: Spray voltage, $3.5 \mathrm{kV}$; S lens level, 50; capillary temperature, $320^{\circ} \mathrm{C}$; sheath, auxiliary, and sweep gas flow, 50, 13, and 3, respectively (arbitrary units); and probe heater temperature, $425^{\circ} \mathrm{C}$. For data treatment, the TraceFinder 5.1. software (Thermo Fisher Scientific, Waltham, MA, USA) was used. The identification was made by comparing (maximum deviation of $5 \mathrm{ppm}$ ) the exact masses of the pseudomolecular ion and their fragment ions with the data contained in an anthocyanins database with 12 possible compounds. The retention time of standard compounds and isotopic pattern scores higher than $80 \%$ were also required. The following anthocyanin standards were used for identification purposes: Cyanidin-3-glucoside, cyanidin-3-galactoside, malvidin3-glucoside, peonidin-3-glucoside, and delphinidin-3-glucoside. Anthocyanin compounds were quantified using the areas of the aglycone counterparts.

\subsection{Cell Culture}

Human colorectal adenocarcinoma, epithelial, adherent (HT-29 cells) provided by the Department of Pharmacology (Seville University, Seville, Spain), were cultured in McCoy's 5a culture medium, and murine macrophage cells, adherent (RAW 264.7 cells) were obtained from Centro Andaluz de Biología Molecular y Medicina Regenerativa (CABIMER, Seville, Spain) and cultured in DMEM high glucose. Both cell lines were supplemented with $10 \%$ FBS $1 \% \mathrm{P} / \mathrm{S}$ and incubated at $37^{\circ} \mathrm{C}$ and $5 \% \mathrm{CO}_{2}$, with the medium changing every 2 days. Cells were maintained in $75 \mathrm{~cm}^{2}$ flasks and, when they reached $80-90 \%$ confluence in the flask, were harvested using trypsin/EDTA $(0.5 \% v / v)$.

\subsection{Viability and Cytotoxic Assays}

Cell viability was determined using the Alamar Blue ${ }^{\circledR}$ reagent (Invitrogen, Carlsbad, CA, USA) based on the quantitative colorimetric assay following the manufacturer's protocols. For all experiments, HT-29 and RAW 264.7 cells were seeded in 24-well plates $(5 \times 105$ cells / well $)$ and incubated for $24 \mathrm{~h}$ to allow the cells to adhere to the plate surface. Ach was prepared in distilled $\mathrm{H}_{2} \mathrm{O}$ and diluted in a cell culture medium. The concentrations of Ach in the in vitro experiments were based on data previously published on fruit extract of other berries [36,37]. Thus, treating the cells with 100, 200, and $300 \mu \mathrm{g} / \mathrm{mL}$ of Ach was chosen. HT-29 cells were exposed to $\mathrm{H}_{2} \mathrm{O}_{2}$ at $0.05 \%$ and incubated with or without Ach at different concentrations during 24 or $48 \mathrm{~h}$. NAC, a known antioxidant, was used as a control. Cell viability of LPS $(1.0 \mu \mathrm{g} / \mathrm{mL})$-induced RAW 264.7 cells was tested to determine the potential cytotoxic effect of increasing concentrations of Ach for $12 \mathrm{~h}$. The 5-aminosalicylic acid (5-ASA), an anti-inflammatory drug, was used as a control according to a previously published work [38]. The culture supernatants were collected, and the 
absorbance of each one was measured at $570 \mathrm{~nm}$ using a microplate reader. The cell viability was calculated as follows:

$$
\text { Cell viability }(\%)=\frac{\text { Abs }(\text { experiment })-\text { Abs }(\text { blank })}{A b s(\text { control })-A b s(\text { blank })} \times 100
$$

\subsection{Determination of Reactive Oxygen Species (ROS) by the DCFH-DA Assay}

A fluorescent $2^{\prime}, 7^{\prime}$-dichlorofluorescein diacetate (DCFH-DA) assay was performed to determine the intracellular ROS concentrations according to the method reported by Miranda-Rottmann [28] with modifications. Cells were seeded at $1 \times 10^{5}$ cells/well in 96-well plates in a final volume of $100 \mu \mathrm{L}$ of culture medium per well. When the cells reached a confluence of $80 \%$, HT-29 and RAW 264.7 cells were incubated with $\mathrm{H}_{2} \mathrm{O}_{2}$ and LPS, respectively in the presence or absence of Ach and internal control (NAC and 5-ASA) for $1 \mathrm{~h}$ with $5 \% \mathrm{CO}_{2}$ at $37^{\circ} \mathrm{C}$. After removing the medium, cells were washed twice with $50 \mu \mathrm{L} /$ well of PBS, incubated at $37{ }^{\circ} \mathrm{C}$ for $30 \mathrm{~min}$ with $25 \mu \mathrm{M}$ DCFH-DA, and stored under at $-20^{\circ} \mathrm{C}$. For the DCFH-DA assay, a culture medium was used without phenol red and without supplementation to avoid interference with fluorescence emission. The fluorescence was measured at Ex/Em: $485 / 530 \mathrm{~nm}$ using a fluorescence microplate reader.

$$
\text { Oxidation }(\%)=\frac{\text { Fluorescence }(\text { experiment })-\text { Fluorescence }(w / \text { o cells })}{\text { Fluorescence }(\text { control })-\text { Fluorescence }(w / \text { cells })} \times 100
$$

\subsection{Statistical Analysis}

The results were expressed as the mean \pm standard error of the mean (SEM) and \pm the standard deviation (SD) according to the particular characteristics of the tests. All experiments were replicated three times. Heterogeneity was tested using Levene's test and the Shapiro-Wilk test for normality. The continuous variables that are normally distributed were compared through the parametric Student $t$-test (two sample $t$-test) and proportions were tested using the two samples test calculator (prtesti). The analysis of differences between groups was evaluated by one-way analysis of variance (ANOVA) tests when the variables were normally distributed, followed by Bonferroni's post-hoc test. Descriptive statistics and tests were performed at a significance level of 0.05 using the STATA software (version 12, 2011, StataCorp, College Station, TX, USA).

\section{Results}

\subsection{Antioxidant Capacity (AC) by DPPH and ORAC of Maqui and Murta in Different Preservation Methods}

The results of the analysis of the $\mathrm{AC}$ of maqui and murta, as estimated by the free radical scavenging through the DPPH method and ORAC assay, are shown in Table 1. Through the DPPH assay it is observed that the AC of maqui, regardless of all different types of preservation methods, is four times higher than murta. In the same way, the ORAC values indicate that maqui has a significantly higher AC than murta in fresh, refrigerated, and frozen samples. When AC of maqui and murta was estimated by these methods, results showed that both berries have greater $\mathrm{AC}$ in fresh and frozen storage, in comparison with the refrigerated state.

\begin{tabular}{|c|c|c|c|c|c|c|}
\hline \multirow{2}{*}{ Sample } & \multicolumn{3}{|c|}{ EC50 for DPPH (mg/mL) } & \multicolumn{3}{|c|}{ ORAC Value (mg TE/g DM) } \\
\hline & Fresh $(x \pm \mathrm{SD})$ & Refrigerated ( $x \pm S D)$ & Frozen $(x \pm \mathrm{SD})$ & Fresh $(x \pm \mathrm{SD})$ & Refrigerated ( $x \pm S D)$ & Frozen $(x \pm \mathrm{SD})$ \\
\hline Maqui & $372.37 \pm 2.52 *$ & $349.05 \pm 1.05^{*}+$ & $364.76 \pm 1.96 *$ & $6.02 \pm 0.04 *$ & $5.93 \pm 0.12 *,+$ & $5.97 \pm 0.56 *$ \\
\hline Murta & $79.68 \pm 1.53$ & $74.72 \pm 0.58^{\dagger}$ & $78.02 \pm 2.04$ & $3.97 \pm 0.06$ & $3.84 \pm 0.06^{\dagger}$ & $4.01 \pm 0.04$ \\
\hline
\end{tabular}

Table 1. DPPH and ORAC assay results for maqui and murta extracts in three categories of preservation.

Data are presented as mean \pm standard deviation (SD); mg TE/g DM: Milligrams of Trolox equivalents per gram of dry mass. * Significant difference $(p<0.05)$ between berries per category of preservation. + Significant decrease $(p<0.05)$ of antioxidant capacity of maqui and murta refrigerated in comparison with fresh and frozen samples. EC50: the half maximal effective concentration; DPPH: 2,2-diphenyl-1picrylhydrazyl; ORAC: oxygen radical absorbance capacity. 


\subsection{Total Polyphenols Content (TPC) of Maqui and Murta in Different Preservation Methods}

The TPC values for maqui and murta estimated by the Folin-Ciocalteu method are shown in Table 2. It can be observed that maqui, with all the preservation methods, showed a significantly higher polyphenol content than murta. The TPC data from refrigerated samples presented the lowest values in comparison with fresh and frozen samples, showing statistical significance. On the other hand, when the data of maqui and murta were compared in fresh versus frozen state, the values were very similar.

Table 2. Quantification values of TPC in maqui and murta by the Folin-Ciocalteu method in three categories of preservation.

\begin{tabular}{cccc}
\hline Sample & $\begin{array}{c}\text { Fresh }(\boldsymbol{x} \pm \text { SD }) \\
\text { mg GAE/g FW }\end{array}$ & $\begin{array}{c}\text { Refrigerated }(\boldsymbol{x} \pm \text { SD }) \\
\text { mg GAE/g FW }\end{array}$ & $\begin{array}{c}\text { Frozen }(\boldsymbol{x} \pm \text { SD }) \\
\text { mg GAE/g FW }\end{array}$ \\
\hline Maqui & $75.348 \pm 1.53^{*}$ & $69.652 \pm 0.58^{*,+}$ & $73.786 \pm 3.06^{*}$ \\
Murta & $48.041 \pm 1.00$ & $42.780 \pm 0.56^{+}$ & $47.309 \pm 2.09$ \\
\hline
\end{tabular}

Data are presented as mean \pm standard deviation (SD); mg GAE/g FW: Milligrams of gallic acid equivalent per gram of fresh weight; TCP: Total polyphenolic content. * Significant difference $(p<0.05)$ between berries per category of preservation. + Significant decrease $(p<0.05)$ of TCP of maqui and murta refrigerated in comparison with fresh and frozen samples.

\subsection{Total Polyphenols Content (TPC) and Antioxidant Capacity (AC) of Polyphenolic Maqui Extract (Ach)}

The most important factors that affect the polyphenol content in fruits are usually genotype, environment, geographical location, and altitude, as well as season, soil, maturity stage at harvest, and post-harvest conditions [20]. The Folin-Ciocalteu method is the most widely used assay for the estimation of TPC in a wide range of samples, including fruits, juices, and wine $[39,40]$. The results of the Folin-Ciocalteu method show that the lyophilized extracts of the maqui fruit content have an average TPC of $39.02 \mathrm{mg} / \mathrm{g}$ of polyphenols expressed as gallic acid. The results regarding the $\mathrm{AC}$ of the maqui extract to reduce $\mathrm{Fe}^{3+}$ to $\mathrm{Fe}^{2+}$, indicate that the Ach has an AC of $69.48 \mathrm{mmol}$ Trolox/100 g sample.

\subsection{Characterization of Extracts}

Characterization of the maqui's anthocyanins extract was performed by the UHPLCMS/MS with an electrospray ionization that enables comparison of $m / z$ signals and fragment ions of the anthocyanin pattern. Regarding the maqui composition, delphinidin-3O-glucoside was the major component $(m / z: 465.1,34.3 \%)$, followed by delphinidin-3,5$O$-diglucoside $(m / z: 627.1,21.2 \%)$, cyanidin-3-O-glucoside $(m / z: 449.1,8.3 \%)$, delphinidin3-O-sambubioside-5-O-glucoside $(\mathrm{m} / \mathrm{z}$ : 759.1, 7.7\%), delphinidin-3-O-sambubioside $(\mathrm{m} / \mathrm{z}$ : 597.1, 7.0\%), cyanidin-3,5-O-diglucoside $(m / z: 611.1,6.2 \%)$, cyanidin-3-O-sambubioside-5$O$-glucoside $(\mathrm{m} / \mathrm{z}: 743.2,3.4 \%)$, cyanidin-3-O-sambubioside $(\mathrm{m} / \mathrm{z}: 581.1,2.3 \%)$, as main components of the extraction procedure performed. Other similar structures identified were malvidin-3-O-glucoside $(\mathrm{m} / \mathrm{z}: 493.1,0.7 \%)$, pelargonidin-3-O-glucoside $(\mathrm{m} / \mathrm{z}$ : $433.1,0.1 \%)$, and peonidin-3-O-glucoside $(\mathrm{m} / \mathrm{z}: 463.1,0.05 \%)$. The anthocyanin profile is shown in Figure 2 and is compared with a previously reported one [20], without finding statistical differences. 


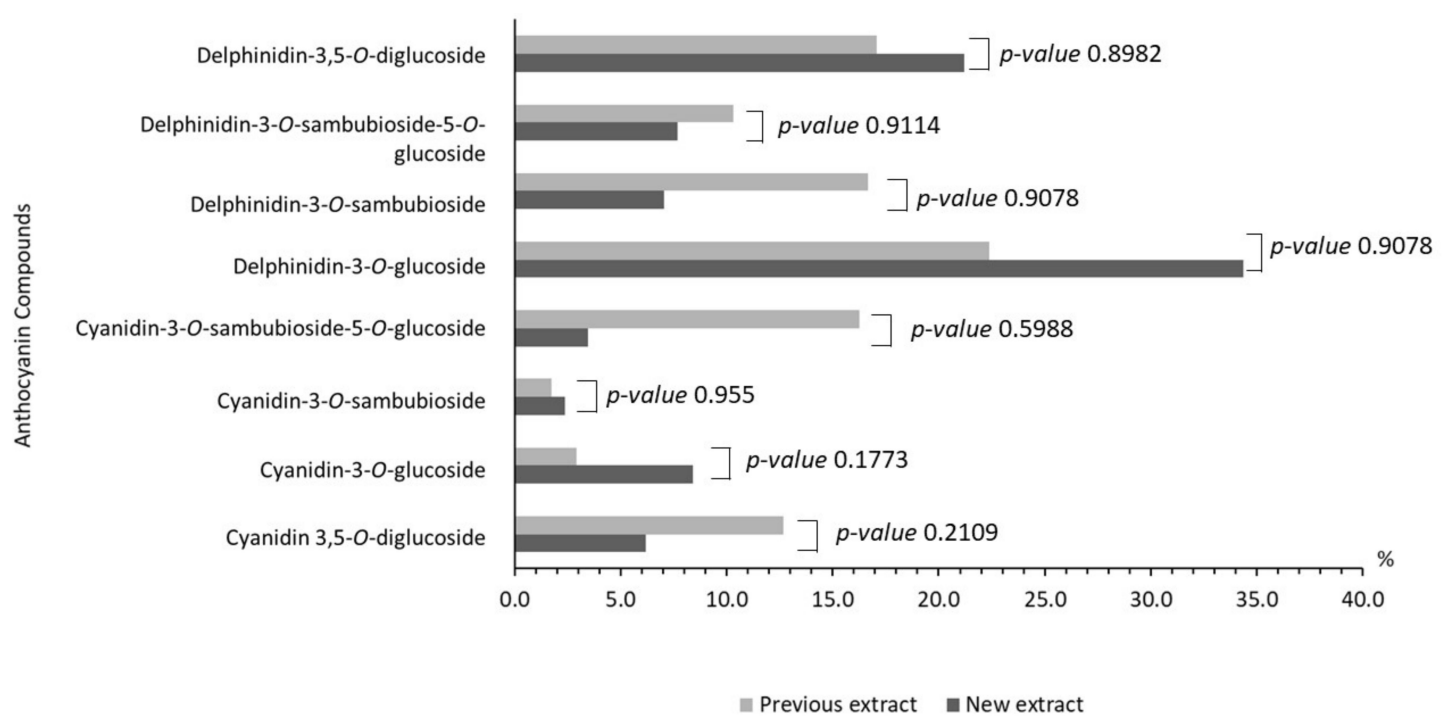

Figure 2. Determination of individual anthocyanin compounds in maqui extract by ultra-high-performance liquid chromatography (UHPLC-MS/MS) Orbitrap. Our data (new extract; dark gray) are presented according to the percentage of anthocyanin compound and compared with the anthocyanins profile previously reported (previous extract; light gray) [20].

\subsection{Viability and Cytotoxicity}

To test the protective effect of maqui, HT-29 cells were incubated with increasing concentrations of Ach for 24 and $48 \mathrm{~h}$ and compared to NAC (Figure 3). Initially, the effect of $\mathrm{H}_{2} \mathrm{O}_{2}$ on epithelial cells was determined revealing a significant reduction ( $p$-value $<0.01$ ) of the viability. When HT-29 cells were incubated with Ach the results showed that all concentrations $(100,200$, and $300 \mu \mathrm{g} / \mathrm{mL})$ tested caused a significant increase of viability at 24 and $48 \mathrm{~h}$. The effect of Ach on cell viability was higher than that of $5 \mathrm{mM} \mathrm{NAC}$. To examine the cytotoxic effects of Ach, the viability of RAW 264.7 macrophages was evaluated at concentrations of 100, 200, and $300 \mu \mathrm{g} / \mathrm{mL}$ of Ach for $24 \mathrm{~h}$. As shown in Figure 4, no notable effects on cell viability in LPS-stimulated RAW 264.7 cells were observed with or without treatment. When comparing Ach with different concentrations of 5-ASA (0.1, 0.5, and $1 \mathrm{mM}$ ) in the presence of LPS, no significant cytotoxicity was found, even when mixing 5-ASA $(0.1 \mathrm{mM})$ and Ach $(100 \mu \mathrm{M} / \mathrm{mL})$.

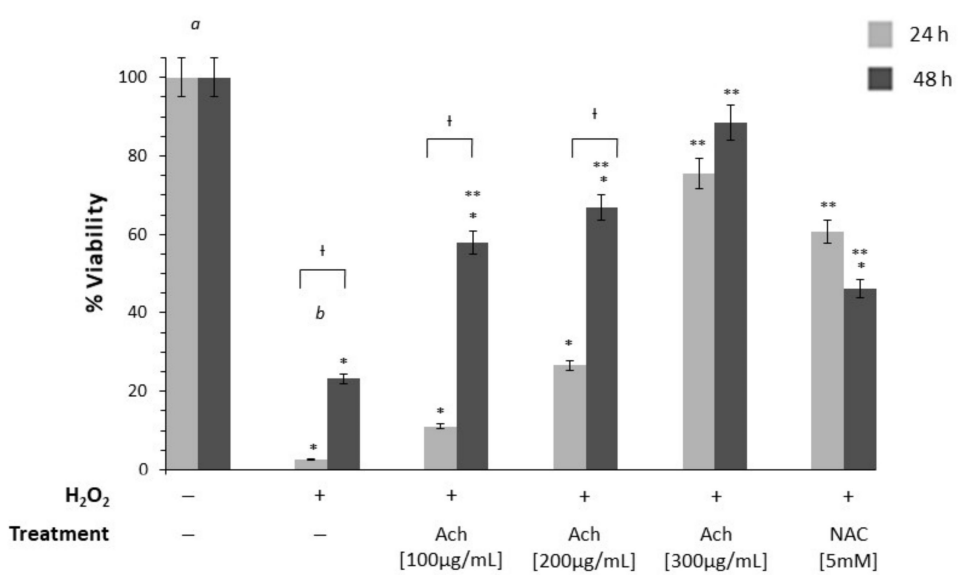

Figure 3. Ach presents a protective effect on the viability of HT-29 cells exposed to $0.05 \% \mathrm{H}_{2} \mathrm{O}_{2}$ and treated during 24 and $48 \mathrm{~h}$ with different concentrations of Ach. The viability of cells without $\mathrm{H}_{2} \mathrm{O}_{2}$ was $100 \%$. Data are expressed as the mean \pm SEM. A $p$-value $<0.01$ was considered statistically significant: * With respect to $a,{ }^{* *}$ with respect to $b$, t between 24 and $48 \mathrm{~h}$. Positive sign (+): presence of treatment; negative sign (-): absence of treatment. 


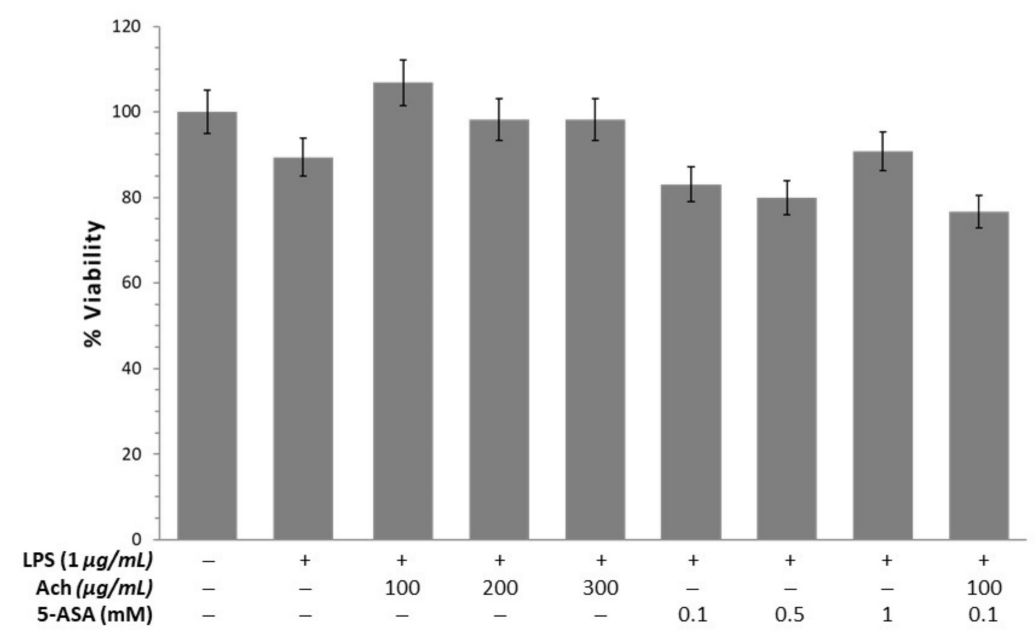

Figure 4. Ach shows no cytotoxicity effects in RAW 264.7 cells treated with lipopolysaccharide (LPS) $(1.0 \mu \mathrm{g} / \mathrm{mL})$. Data are expressed as the mean \pm SEM. The viability of cells without LPS was $100 \%$. Positive sign (+): presence of treatment; negative sign (-): absence of treatment.

\subsection{Oxidative Stress}

Figure 5 shows a significant increase of oxidation in HT-29 cells when $\mathrm{H}_{2} \mathrm{O}_{2}(p$-value $<0.05)$ was added. These results were inhibited by all concentrations of Ach in a dose-dependent way, reaching significance at $300 \mu \mathrm{g} / \mathrm{mL}$. In parallel, when epithelial cells exposed to $\mathrm{H}_{2} \mathrm{O}_{2}$ were treated with NAC, it was possible to observe a decrease in oxidation, although not significant. In RAW 264.6 macrophages, LPS stimulation led to the increment of oxidation, demonstrating the relationship between inflammation and OS (Figure 6). Ach effectively suppressed the LPS-induced oxidation in a dose-dependent manner, showing a significant reduction with the highest doses $(200$ and $300 \mu \mathrm{g} / \mathrm{mL}$ ). At the same time, these results indicated that the suppression of oxidation could not be attributable to the direct cytotoxic effect of Ach. Of interest is the fact that the $0.1 \mathrm{mM}$ of 5-ASA plus $300 \mu \mathrm{g} / \mathrm{mL}$ of Ach concentration had an inhibition effect comparable to the control conditions (cells in culture medium without LPS), achieving values of basal oxidative state.

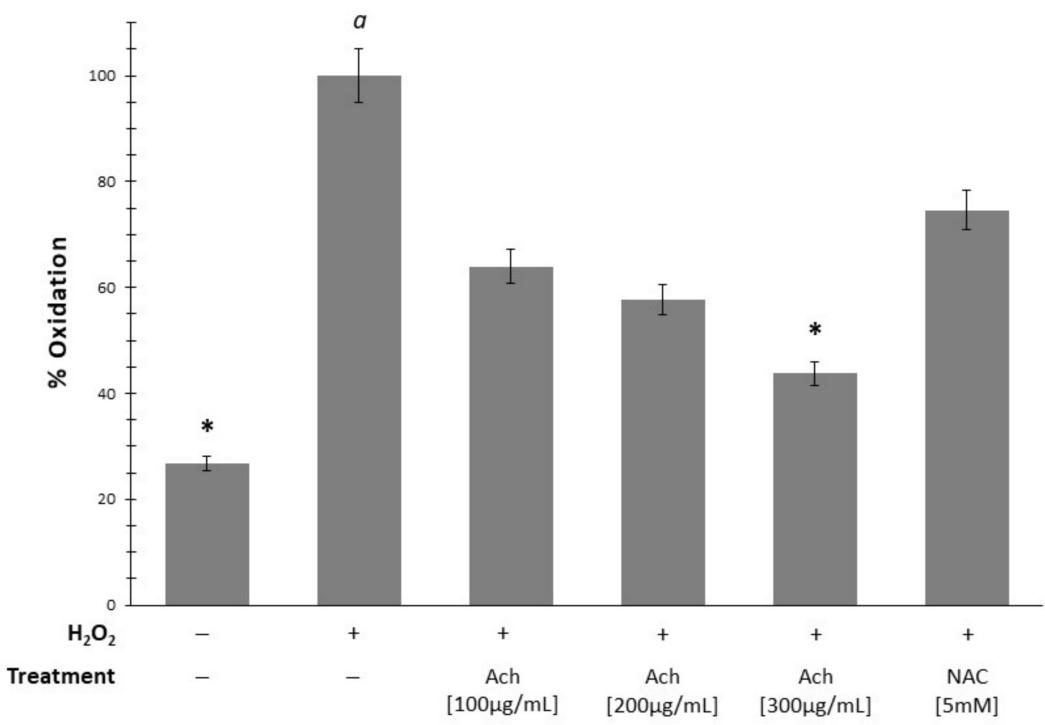

Figure 5. Supplementation with Ach to HT-29 cells stressed with $0.05 \% \mathrm{H}_{2} \mathrm{O}_{2}$ decreases oxidation status in a dose-dependent manner, and more efficiently than NAC. Data are expressed as the mean \pm SEM and the measured percent oxidation were expressed as a percentage from the positive control (cells induced by $\mathrm{H}_{2} \mathrm{O}_{2}$ ). ${ }^{*} \mathrm{~A} p$-value $<0.05$ indicates significant differences with respect to $a$. Positive sign $(+)$ : presence of treatment; negative sign $(-)$ : absence of treatment. 


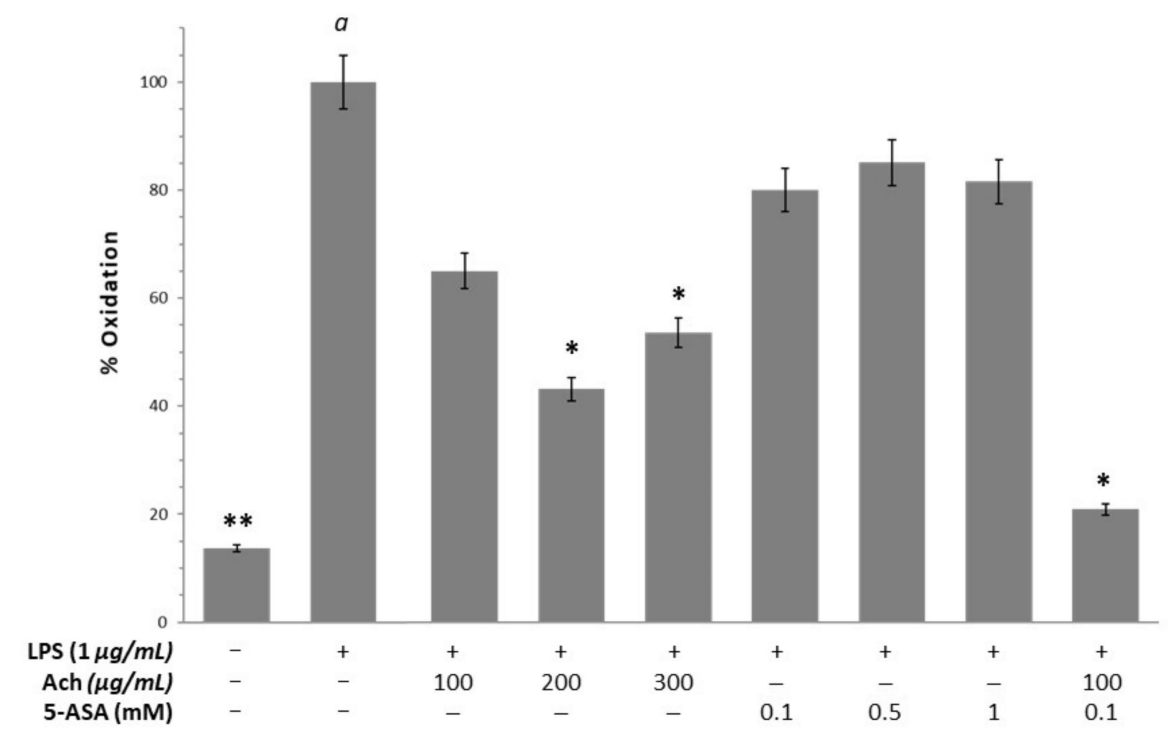

Figure 6. Ach inhibits oxidative stress in RAW 264.7 macrophages stimulated with LPS $(1.0 \mu \mathrm{g} / \mathrm{mL})$. The cells incubated with Ach $(100 \mu \mathrm{g} / \mathrm{mL})$ plus 5-aminosalicylic acid (5-ASA) (5 mM) presented the lowest percentage of oxidation. Data are expressed as the mean \pm SEM and the measured percent oxidation were expressed as a percentage from the positive control (cells induced by H2O2). ${ }^{*} \mathrm{~A}$ $p$-value $<0.05$ and ${ }^{* *} p$-value $<0.01$ indicate significant differences with respect to $a$. Positive sign $(+)$ : presence of treatment; negative sign (-): absence of treatment.

\section{Discussion}

The polyphenolic content in several berries has been widely proved to be the major contributor to AC $[39,41]$ and the way of consumption (fresh, processed or stored for long-term) could be relevant to preserve polyphenol compounds and its beneficial effects, including other phytochemicals that also play a critical role. In the present work, it was demonstrated that maqui has greater AC than murta, and significant differences of TCP in fresh fruit values, with $75.3 \mathrm{mg}$ GAE/g FW for maqui and $48.0 \mathrm{mg}$ GAE/g FW for murta. These findings are in agreement with Salvia-Trujillo et al. [42] who reported a depletion of antioxidant "Vitamin C" during refrigerated storage, which was correlated with AC. Additionally, other studies reported that polyphenols from crude extracts of maqui were also much higher than crude extracts from murta [12], and that maqui fruit does not decrease polyphenol and anthocyanin contents during desiccation, cooling or freezing processes [43].

Maqui has been selected for further investigation based on AC and TPC results. The raw material was a marketed maqui product (native, fresh, and lyophilized maqui powder). In order to evaluate the activities of maqui berry extracts as an antioxidant and anti-inflammatory potential agent, a modified procedure was implemented to develop a multigram and more efficient methodology to provide appropriated quantities. The extraction procedure described here is based on a $50 \mathrm{~g}$ scale for the first time, and many laboratory operations have been reduced to simplify and minimize economic costs and increase safety, since less solvents are manipulated. The reproducibility of this procedure was confirmed via all the analyses carried out of the numerous batches obtained, preserving in all cases the TPC and AC characteristics due to low temperatures and darkness along all the processes. The multigram procedure involves an improvement of the previous method published by Viuda-Martos et al. [20], in which $3 \mathrm{~g}$ of lyophilized and ground maqui berry were used to test antibacterial properties. Other studies submitted $1 \mathrm{~g}$ to solid-liquid extraction, such as in the procedure recently described by Silvia Rossi et al. [30], that uses this extract embedded in an appropriate gel for a better delivery for inflammatory bowel disease. Moreover, $1.5 \mathrm{~g}$ were extracted by Fredes et al. [40] to evaluate how the maturation affects the TPC. In general, all the procedures are based on the same type 
of extraction and all of them used an aqueous methanol acidic mixture, choosing either $\mathrm{HCl}$ or formic acid to accomplish a better polyphenolic extraction. Interestingly, no high temperatures above $50{ }^{\circ} \mathrm{C}$ are used in any of them, since as previously described, it might be expected that the temperature during thermal drying technologies contributed to the loss of phenols. Temperatures above $60^{\circ} \mathrm{C}$ are not favorable owing to inducing oxidative condensation/decomposition of thermolabile components. Additionally, the drying method such as lyophilization preserves TPC as described by Quispe et al. [21]. It is well known that the Folin-Ciocalteu method is the most common analysis to estimate the TPC in many fruits and foods and also shows a good linear correlation to the anthocyanin content described by HPLC [44]. Although this method often overestimates the phenol content due to the presence of $L$-ascorbic acid (vitamin C) fortunately, it has been well established that maqui would not present this interference since no traces of vitamin $C$ has been detected in maqui fruit, according to Miranda-Rottmann et al. [28]. In this sense, the TPC obtained in this study was $39.02 \mathrm{mg} / \mathrm{g}$. Genskowsky et al. [20] described the three main groups of polyphenolic compounds in maqui berries such as phenolic acids, flavonoids, and anthocyanins, identifying a TPC of $49.49 \mathrm{~g} \mathrm{GAE} / \mathrm{kg}$, while Reyes-Farias et al. [45] published a TPC of $19.06 \mathrm{mg} / \mathrm{g}$, much higher values when compared with other native Chilean berries and traditional berries such as blueberries [39]. Moreover, in different maqui genotypes belonging to four different geographical regions in Chile, TPC values ranged between 11.1 and $14.5 \mathrm{mg} / \mathrm{g}$. Brauch et al. reported that data for fresh and dry maqui berries, collected in the Aysén region (Patagonia, Chile), displaying values between 19.7 and $32.0 \mathrm{mg} / \mathrm{g}$, were always referred to as gallic acid equivalents. On the other hand, and as previously mentioned, TPC is affected by various factors related to maqui such as genotype, environment, storage, and processing or stage at harvest. Hence, fruits with different maturity stages have different types or contents of polyphenols. Our maqui berry extract comes from the sylvester variety, which interestingly has been described as the one that contains more polyphenols if compared with the other varieties named as "Luna Nueva" and "Morena" [19]. Moreover, when the phenolic content of maqui is compared with different varieties of berries, including red wine as it is a known rich source of dietary phenols, it is possible to observe that the maqui fruit is superior, even when compared with fruits of habitual consumption, showing the maqui difference values of up to 80 times $[28,45]$.

In addition, the AC expressed as FRAP of our maqui berry extract was determined following the method previously described. The results indicate that the maqui extract has an AC of 69.48, expressed as mmol Trolox equivalent/100 $\mathrm{g}$ of dried sample regarding the $\mathrm{AC}$ of the maqui extract to reduce $\mathrm{Fe}^{3+}$ to $\mathrm{Fe}^{2+}$. When the $\mathrm{AC}$ of Ach is compared with other berries, it is possible to observe significant differences, with a ferric reduction potential of $69.48 \mathrm{mmol}$ Trolox $/ 100 \mathrm{~g}$ compared to blueberries, which have a value of $5.9 \mathrm{mmol} \mathrm{Fe} \mathrm{e}^{+2} / 100 \mathrm{~g}$ dry weight [45]. Moreover, our data is much better than the other maqui extracts previously reported, that have shown FRAP values of $10.07 \mathrm{mmol}$ Trolox/100 g [20]. Interestingly, maqui has several phytochemicals, particularly anthocyanins, a set of water-soluble pigments, which represent more than $65 \%$ of the total polyphenols that are responsible for the intense red to purplish-blue color of several fruits and that are influenced by $\mathrm{pH}$, light or temperature. Recent studies have demonstrated that the most abundant compounds of maqui are delphinidin derivatives and cyanidin derivatives. In this sense, in the analytical UHPLC-MS/MS semi quantitative determination, the profile obtained from the maqui composition extract concerning this study was compared to the previously described study by Genskowsky et al. [20], who used a smaller extraction procedure (Figure 2). In general terms, the concentration obtained in both cases for most of the components coincide. Specifically, among the most abundant are delphinidin-3-O-glucoside, delphinidin-3,5-O-diglucoside, cyanidin-3-O-glucoside or delphinidin-3-O-sambubioside-5-O-glucoside. Other similar structures identified for the first time as part of a maqui extract, to our knowledge, were malvidin-3-O-glucoside, 
pelargonidin-3-O-glucoside, and peonidin-3-O-glucoside, that represent in sum $0.85 \%$ of the total composition.

The effect of polyphenolic maqui extract, related to the different mechanisms associated with inflammation and oxidation has also been described in the literature (Table 3). Once the total chemical structural determination and characterization were demonstrated, in vitro studies were carried out to investigate the biological role of these entities as potential therapeutic agents relative to OS. In this sense, it has been suggested that OS is involved in the pathogenesis and development of IBD through many levels such as cell transformation, apoptosis, DNA damage, and pro-inflammatory response [7]. Additionally, polyphenols suppress inflammation-related gene expression, downregulate proinflammatory cytokine expression, and increase the production and effects of anti-inflammatory cytokines [46].

Table 3. Anti-inflammatory and antioxidant effect of maqui berry extract described on cell cultures.

\begin{tabular}{|c|c|c|c|c|c|}
\hline Reference & Cell Culture & Model & Extract & Concentration & Effects \\
\hline $\begin{array}{c}\text { Zhou G. et al. } 2019 \\
\text { [29] }\end{array}$ & $\begin{array}{c}\text { RAW } 264.7 \\
\text { macrophage cells }\end{array}$ & $\begin{array}{c}\text { Inflammatory } \\
\text { model with LPS } \\
\text { stimulated for } 24 \mathrm{~h}\end{array}$ & $\begin{array}{l}\text { Water fraction } \\
\text { extract with ethyl } \\
\text { acetate rich in } \\
\text { phenols }\end{array}$ & $2-20 \mu \mathrm{g} \mathrm{ml}^{-1}$ & $\begin{array}{c}\downarrow \mathrm{COX}-2 \\
\downarrow \text { IL-6 }\end{array}$ \\
\hline $\begin{array}{c}\text { Tenci M. et al. } 2019 \\
\text { [30] }\end{array}$ & $\begin{array}{l}\text { Fibroblasts } \\
\text { and Caco-2 }\end{array}$ & $\begin{array}{c}\text { Oxidant model } \\
\text { with } \mathrm{H}_{2} \mathrm{O}_{2}(1 \mathrm{mM}) \\
\text { for } 24 \mathrm{~h}\end{array}$ & $\begin{array}{c}\text { MBE with acid } \\
\text { MeOH 0.1\% } \\
\left(\mathrm{H}_{2} \mathrm{O}: \mathrm{MeOH} / 10: 90\right. \\
v / v) \text { rich in } \\
\text { anthocyanins }\end{array}$ & $\begin{array}{c}\text { MBE solution } \\
(0.5 \% w / w) \text { diluted } \\
\text { at } 1: 2, \text { and } 1: 5 v / v\end{array}$ & $\begin{array}{l}\text { No cytotoxic effect } \\
\text { Viability under } \\
\text { oxidative damage }\end{array}$ \\
\hline $\begin{array}{l}\text { Moon HD. et al. } \\
2019 \text { [47] }\end{array}$ & $\begin{array}{c}\text { RAW } 264.7 \\
\text { macrophage cells }\end{array}$ & $\begin{array}{c}\text { Inflammatory } \\
\text { model with LPS } \\
\text { stimulated for } 24 \mathrm{~h} \\
(0.1 \mu \mathrm{g} / \mathrm{mL})\end{array}$ & $\begin{array}{l}\text { Water extract of } \\
\text { maqui rich in } \\
\text { anthocyanins }\end{array}$ & $\begin{array}{c}62.5,125,250,500 \\
1000, \text { and } 2000 \\
\mu \mathrm{g} / \mathrm{ml}\end{array}$ & $\downarrow N O$ \\
\hline $\begin{array}{c}\text { Céspedes, C.L., } \\
\text { et al. } 2017 \\
{[24]}\end{array}$ & $\begin{array}{c}\text { RAW } 264.7 \\
\text { macrophage cells }\end{array}$ & $\begin{array}{c}\text { Inflammatory } \\
\text { model with LPS } \\
\text { stimulated for } 24 \mathrm{~h} \\
(1 \mu \mathrm{g} / \mathrm{mL})\end{array}$ & $\begin{array}{l}\text { Pulp extract with } \\
\text { acid } \mathrm{MeOH} 0.1 \% \\
\left.\mathrm{HCl}: \mathrm{H}_{2} \mathrm{O} / 6: 4 \mathrm{v} / \mathrm{v}\right) \\
\text { Acetone } / \mathrm{MeOH} ; \\
\text { Ethyl acetate }\end{array}$ & $100 \mu \mathrm{g} / \mathrm{ml}$ & $\begin{array}{c}\text { No cytotoxic effect } \\
\downarrow \text { Oxidation } \\
\downarrow \text { NO } \\
\downarrow \text { iNOS } \\
\downarrow \text { COX-2 }\end{array}$ \\
\hline $\begin{array}{l}\text { Reyes-Farias, M., } \\
\text { et al. } 2015 \text { [45] }\end{array}$ & $\begin{array}{c}\text { RAW } 264.7 \\
\text { macrophage cells }\end{array}$ & $\begin{array}{c}\text { Inflammatory } \\
\text { model with LPS } \\
\text { stimulated for } 24 \mathrm{~h} \\
(5 \mu \mathrm{g} / \mathrm{mL}) \text { or with } \\
\mathrm{CM} \text { from fully } \\
\text { differentiated } \\
\text { 3T3-L1 adipocytes }\end{array}$ & $\begin{array}{c}\text { TCP: from Ripe } \\
\text { fruits extract with } \\
\text { acid } \\
\text { MeOH: } \mathrm{H}_{2} \mathrm{O} / 1: 1 \\
v / v)\end{array}$ & $100 \mu \mathrm{M}$ & $\begin{array}{c}\text { CM: } \\
\downarrow \text { NO; iNOS } \\
\uparrow \text { TNF- } \alpha \text {; IL-10 } \\
\text { LPS: } \\
\downarrow \text { NO; iNOS; } \\
\text { TNF- } \alpha \text {; IL-10 }\end{array}$ \\
\hline \multirow{2}{*}{$\begin{array}{c}\text { Miranda- } \\
\text { Rottmann S. et al. } \\
2002 \\
{[28]}\end{array}$} & \multirow{2}{*}{$\begin{array}{c}\text { Primary culture of } \\
\text { HUVEC }\end{array}$} & $\begin{array}{l}\text { Vascular OS model } \\
\text { with } 500 \mu \mathrm{M} \mathrm{H}_{2} \mathrm{O}_{2}\end{array}$ & \multirow{2}{*}{$\begin{array}{l}\text { Aqueous fraction } \\
\text { juice extract with } \\
\text { ethyl acetate at } \mathrm{pH} \\
2.0 \text { rich in } \\
\text { anthocyanins }\end{array}$} & $0.1-10 \mu \mathrm{M}$ & $\downarrow$ intracellular OS \\
\hline & & $\begin{array}{l}\text { Copper-induced } \\
\text { LDL oxidation } \\
\text { in vitro }\end{array}$ & & $1 \mu \mathrm{M}$ GAE & $\downarrow$ LDL oxidation \\
\hline
\end{tabular}

(LPS): lipopolysaccharide; CM: conditioned media; OS: oxidative stress; LDL: low-density lipoprotein; MBE: maqui berry extract; TCP: total polyphenolic content; COX-2: cyclooxygenase-2; IL-6: interleukin-6; NO: nitric oxide; iNOS: inducible nitric oxide synthase; TNF- $\alpha$ : tumor necrosis factor- $\alpha$; IL-10: interleukin-10.

Studies in culture cells exposed to $\mathrm{H}_{2} \mathrm{O}_{2}$ are a good model of OS since $\mathrm{H}_{2} \mathrm{O}_{2}$ is catalyzed by $\mathrm{Fe}^{2+}$ (Fenton reaction) to the highly reactive hydroxyl radical $\left(\mathrm{HO}^{\bullet}\right)$. However, the loss of cell viability or lipid peroxidation in epithelial cells are achieved when cells are incubated at a concentration above $250 \mu \mathrm{M} \mathrm{H}_{2} \mathrm{O}_{2}$ [48]. Therefore, a higher concentration of $500 \mu \mathrm{M}(0.05 \%)$ for inducing oxidation and death cell in HT-29 cells was used. In the present study, we found a significant improvement in cell viability and reduction of OS when the HT- 29 cells were treated with Ach, finding the main effects at doses of 
$300 \mu \mathrm{g} / \mathrm{mL}$ and at $48 \mathrm{~h}$. These results indicated that the effects of Ach on HT-29 cells are both concentration and time dependent, probably due to the cellular uptake sustained over time, allowing the recovery of cell damage. These results are consistent with previous ones reported by Miranda-Rottmann et al. [28], where incubation with Ach juice prior to the addition of $500 \mu \mathrm{M} \mathrm{H}_{2} \mathrm{O}_{2}$ in HUVEC cells significantly reduces oxidation in a dosedependent manner compared to endothelial cells exposed to $\mathrm{H}_{2} \mathrm{O}_{2}$ without treatment. Furthermore, a previous study has reported that the red wine polyphenol extract did not affect the viability of HT-29 cells at several concentrations $\left(200,400\right.$, and $\left.600 \mu \mathrm{g} / \mathrm{mL}^{-1}\right)$ [49], suggesting the absence of cytotoxic profile. However, higher concentrations of polyphenols such as resveratrol could induce cell death by diverse mechanisms in tumor cell lines, including colorectal cancer cells and, acting as a direct cytotoxic agent [50]. In addition, macrophages have an important role in an inflammatory response and are the central cells that initiate the production of inflammatory mediators. Macrophages stimulated with LPS, viruses, and bacterial endotoxin are able to release inflammatory factors including prostaglandin, proinflammatory cytokines, and ROS. Therefore, the regulation of the level of these factors has become vital for the treatment of inflammatory diseases [51]. In this study, we demonstrated that our extract (Ach) presented a protective activity against OS (DCF) on RAW 264.7 cells, along with the absence of cytotoxicity effect, in the same way as reported by Cespedes et al. [24]. Moreover, it has been demonstrated that other natural products decrease intracellular ROS levels in LPS-stimulated macrophages [52,53], indicating the close relationship between oxidative mechanisms and inflammation. An experimental study published by Zhou et al. [29] showed that the ethyl acetate fraction of maqui extract (MWE) contained a high content of total phenols and flavonoid and that exhibited stronger antioxidant activities than the other extracts such as $n$-butanol fraction. Additionally, the authors proved that MWE considerably reduced the expression of COX-2 and IL-6 in LPS-stimulated RAW 264.7 cells, demonstrating the anti-inflammatory effect. In addition, interestingly, in our work it was possible to show that when we used lower concentrations of Ach and a lower dose of 5-ASA the results on the percent oxidation was significantly lower compared to the control group and the other doses. This effect could indicate synergistic effects between Ach and 5-ASA. The finding of this synergy is very interesting since it opens the possibility of a combination therapy with lower doses of 5-ASA, which will lead to less side effects of this drug used in IBD patients. Furthermore, in agreement with other authors [49], we believe that the protective effect of our extract rich in total polyphenols may be due to the sum of all its components probably due to a synergic action of anthocyanins compounds suggesting that the use of total extracts in polyphenolic compounds, rather than pure polyphenols, could be a better alternative or complementary therapeutic option.

\section{Conclusions}

Our study shows that Chilean berries, specifically maqui, is a potential source of natural antioxidants and that the preservation method seems to be crucial in maintaining the AC in native berries, with fresh and frozen being the best conditions. In this study, a fresh maqui berry extract procedure has been optimized for the first time in multigram scale (50 g) via a simplified and easily reproductible laboratory procedure. The extract profile has been analyzed to quantify the TCP and AC, as well as to prove that this method fulfills the data standard previously described for smaller procedures. All these data confirm that our extraction procedure not only increases the amount of dried extract amount, but also assures an efficient process that preserves the total polyphenols, anthocyanins profile, and antioxidant properties. Interestingly, our studies in activated macrophage and epithelial colon cell cultures have shown that the maqui polyphenolic extract is a powerful antioxidant that exhibits a dose-dependent behavior and no cytotoxic effects, due to the ability to reduce ROS. In addition, our maqui extract seems to have a synergistic effect with 5-ASA, a drug of clinical use in IBD. These findings point out to a possible mechanism of action related to reduce ROS and its relationship with inflammation. However, more 
information concerning higher $n$ values and better determination of endogenous AC will be reported by our group in due course.

In summary, maqui extracts could introduce bioactive candidates for further investigation as potential anti-inflammatory agents. Nevertheless, additional studies are necessary to analyze the effects on bioaccessibility or bioavailability of the bioactive compounds that are under current investigation in our group.

Author Contributions: Conceptualization, F.A.-A., M.D.-M., and A.A.; investigation, T.O., A.P., M.V., V.V.-R., J.L.P.B., R.M.C. and A.A.; writing-original draft preparation, T.O. and A.A.; writing-review and editing, T.O., B.B., J.-M.G.-M., V.V.-R. and M.D.-M.; supervision and project administration, M.D.-M. and A.A. All authors have read and agreed to the published version of the manuscript.

Funding: This work was supported by Sociedad Andaluza de Patología Digestiva 2016 (SAPD), project 2018/00000802-CTS949 (Junta de Andalucía, Spain); Ministerio de Ciencia e Innovación, project PID2019-109371GB-I00, project 2017/FQM-135 (Junta de Andalucía, Spain), and CITIUS facilities (University of Seville, Plan Propio de Investigación); Universidad del Desarrollo, project 2011090814104630378.

Institutional Review Board Statement: Not applicable.

Informed Consent Statement: Not applicable.

Data Availability Statement: Not applicable.

Conflicts of Interest: The authors declare no conflict of interest.

\section{References}

1. Hanauer, S.B. Inflammatory bowel disease: Epidemiology, pathogenesis, and therapeutic opportunities. Inflamm. Bowel Dis. 2006, 12, S3-S9. [CrossRef] [PubMed]

2. Kaplan, G.G. The global burden of IBD: From 2015 to 2025. Nat. Rev. Gastroenterol. Hepatol. 2015, 12, 720-727. [CrossRef]

3. Garber, A.; Regueiro, M. Extraintestinal Manifestations of Inflammatory Bowel Disease: Epidemiology, Etiopathogenesis, and Management. Curr. Gastroenterol. Rep. 2019, 21, 31. [CrossRef] [PubMed]

4. Cui, G.; Yuan, A. A Systematic Review of Epidemiology and Risk Factors Associated With Chinese Inflammatory Bowel Disease. Front. Med. 2018, 5, 183. [CrossRef]

5. Patlevic, P.; Vaskova, J.; Svorc, P., Jr.; Vasko, L.; Svorc, P. Reactive oxygen species and antioxidant defense in human gastrointestinal diseases. Integr. Med. Res. 2016, 5, 250-258. [CrossRef] [PubMed]

6. Masoodi, H.; Villaño, D.; Zafrilla, P. A comprehensive review on fruit Aristotelia chilensis (Maqui) for modern health: towards a better understanding. Food Funct. 2019, 10, 3057-3067. [CrossRef]

7. Tian, T.; Wang, Z.; Zhang, J. Pathomechanisms of Oxidative Stress in Inflammatory Bowel Disease and Potential Antioxidant Therapies. Oxid. Med. Cell. Longev. 2017, 2017, 4535194. [CrossRef]

8. Michalska, A.; Lysiak, G. Bioactive Compounds of Blueberries: Post-Harvest Factors Influencing the Nutritional Value of Products. Int. J. Mol. Sci. 2015, 16, 18642-18663. [CrossRef] [PubMed]

9. Nile, S.H.; Park, S.W. Edible berries: Bioactive components and their effect on human health. Nutrition 2014, 30, 134-144. [CrossRef]

10. Mijan, M.A.; Lim, B.O. Diets, functional foods, and nutraceuticals as alternative therapies for inflammatory bowel disease: Present status and future trends. World J. Gastroenterol. 2018, 24, 2673-2685. [CrossRef]

11. Hu, Y.; Chen, D.; Zheng, P.; Yu, J.; He, J.; Mao, X.; Yu, B. The Bidirectional Interactions between Resveratrol and Gut Microbiota: An Insight into Oxidative Stress and Inflammatory Bowel Disease Therapy. BioMed Res. Int. 2019, 2019, 5403761. [CrossRef] [PubMed]

12. Rubilar, M.; Jara, C.; Poo, Y.; Acevedo, F.; Gutierrez, C.; Sineiro, J.; Shene, C. Extracts of Maqui (Aristotelia chilensis) and Murta (Ugni molinae Turcz.): Sources of antioxidant compounds and alpha-Glucosidase/alpha-Amylase inhibitors. J. Agric. Food Chem. 2011, 59, 1630-1637. [CrossRef] [PubMed]

13. Romero-González, J.; Shun Ah-Hen, K.; Lemus-Mondaca, R.; Muñoz-Fariña, O. Total phenolics, anthocyanin profile and antioxidant activity of maqui, Aristotelia chilensis (Mol.) Stuntz, berries extract in freeze-dried polysaccharides microcapsules. Food Chem. 2020, 313, 126115. [CrossRef] [PubMed]

14. Ortiz, T.; Argüelles-Arias, F.; Illanes, M.; García-Montes, J.M.; Talero, E.; Macías-García, L.; Alcudia, A.; Vázquez-Román, V.; Motilva, V.; De-Miguel, M. Polyphenolic Maqui Extract as a Potential Nutraceutical to Treat TNBS-Induced Crohn's Disease by the Regulation of Antioxidant and Anti-Inflammatory Pathways. Nutrients 2020, 12, 1752. [CrossRef] [PubMed]

15. Junqueira-Goncalves, M.P.; Yanez, L.; Morales, C.; Navarro, M.; Contreras, R.A.; Zuniga, G.E. Isolation and characterization of phenolic compounds and anthocyanins from Murta (Ugni molinae Turcz.) fruits. Assessment of antioxidant and antibacterial activity. Molecules 2015, 20, 5698-5713. [CrossRef] [PubMed] 
16. Speisky, H.; Lopez-Alarcon, C.; Gomez, M.; Fuentes, J.; Sandoval-Acuna, C. First web-based database on total phenolics and oxygen radical absorbance capacity (ORAC) of fruits produced and consumed within the south Andes region of South America. J. Agric. Food Chem. 2012, 60, 8851-8859. [CrossRef]

17. Syamaladevi, R.M.; Andrews, P.K.; Davies, N.M.; Walters, T.; Sablani, S.S. Storage effects on anthocyanins, phenolics and antioxidant activity of thermally processed conventional and organic blueberries. J. Sci. Food Agric. 2012, 92, 916-924. [CrossRef]

18. Jiang, B.; Mantri, N.; Hu, Y.; Lu, J.; Jiang, W.; Lu, H. Evaluation of bioactive compounds of black mulberry juice after thermal, microwave, ultrasonic processing, and storage at different temperatures. Food Sci. Technol. Int. 2015, 21, 392-399. [CrossRef]

19. Brauch, J.E.; Reuter, L.; Conrad, J.; Vogel, H.; Schweiggert, R.M.; Carle, R. Characterization of anthocyanins in novel Chilean maqui berry clones by HPLC-DAD-ESI/MSn and NMR-spectroscopy. J. Food Compos. Anal. 2017, 58, 16-22. [CrossRef]

20. Genskowsky, E.; Puente, L.A.; Perez-Alvarez, J.A.; Fernandez-Lopez, J.; Munoz, L.A.; Viuda-Martos, M. Determination of polyphenolic profile, antioxidant activity and antibacterial properties of maqui (Aristotelia chilensis (Molina) Stuntz) a Chilean blackberry. J. Sci. Food Agric. 2016, 96, 4235-4242. [CrossRef]

21. Quispe-Fuentes, I.; Vega-Gálvez, A.; Aranda, M. Evaluation of phenolic profiles and antioxidant capacity of maqui (Aristotelia chilensis) berries and their relationships to drying methods. J. Sci. Food Agric. 2018, 98, 4168-4176. [CrossRef] [PubMed]

22. Céspedes, C.; El-Hafidi, M.; Pavon, N.; Alarcon, J. Antioxidant and cardioprotective activities of phenolic extracts from fruits of Chilean blackberry Aristotelia chilensis (Elaeocarpaceae), Maqui. Food Chem. 2008, 107, 820-829. [CrossRef]

23. Chang, S.K.; Alasalvar, C.; Shahidi, F. Superfruits: Phytochemicals, antioxidant efficacies, and health effects-A comprehensive review. Crit. Rev. Food Sci. Nutr. 2019, 59, 1580-1604. [CrossRef] [PubMed]

24. Cespedes, C.L.; Pavon, N.; Dominguez, M.; Alarcon, J.; Balbontin, C.; Kubo, I.; El-Hafidi, M.; Avila, J.G. The chilean superfruit black-berry Aristotelia chilensis (Elaeocarpaceae), Maqui as mediator in inflammation-associated disorders. Food Chem. Toxicol. 2017, 108, 438-450. [CrossRef] [PubMed]

25. Escribano-Bailon, M.T.; Alcalde-Eon, C.; Munoz, O.; Rivas-Gonzalo, J.C.; Santos-Buelga, C. Anthocyanins in berries of Maqui (Aristotelia chilensis (Mol.) Stuntz). Phytochem. Anal. 2006, 17, 8-14. [CrossRef] [PubMed]

26. Gironés-Vilaplana, A.; Mena, P.; García-Viguera, C.; Moreno, D.A. A novel beverage rich in antioxidant phenolics: Maqui berry (Aristotelia chilensis) and lemon juice. LWT 2012, 47, 279-286. [CrossRef]

27. Céspedes, C.L.; Valdez-Morales, M.; Avila, J.G.; El-Hafidi, M.; Alarcón, J.; Paredes-López, O. Phytochemical profile and the antioxidant activity of Chilean wild black-berry fruits, Aristotelia chilensis (Mol) Stuntz (Elaeocarpaceae). Food Chem. 2010, 119, 886-895. [CrossRef]

28. Miranda-Rottmann, S.; Aspillaga, A.A.; Perez, D.D.; Vasquez, L.; Martinez, A.L.; Leighton, F. Juice and phenolic fractions of the berry Aristotelia chilensis inhibit LDL oxidation in vitro and protect human endothelial cells against oxidative stress. J. Agric. Food Chem. 2002, 50, 7542-7547. [CrossRef]

29. Zhou, G.; Chen, L.; Sun, Q.; Mo, Q.-G.; Sun, W.-C.; Wang, Y.-W. Maqui berry exhibited therapeutic effects against DSS-induced ulcerative colitis in C57BL/6 mice. Food Funct. 2019, 10, 6655-6665. [CrossRef]

30. Tenci, M.; Rossi, S.; Giannino, V.; Vigani, B.; Sandri, G.; Bonferoni, M.C.; Daglia, M.; Longo, L.M.; Macelloni, C.; Ferrari, F. An In Situ Gelling System for the Local Treatment of Inflammatory Bowel Disease (IBD). The Loading of Maqui (Aristotelia Chilensis) Berry Extract as an Antioxidant and Anti-Inflammatory Agent. Pharmaceutics 2019, 11, 611. [CrossRef]

31. Brand-Williams, W.; Cuvelier, M.E.; Berset, C. Use of a Free Radical Method to Evaluate Antioxidant Activity. LWT Food Sci. Technol. 1995, 28, 25-30. [CrossRef]

32. Zheng, W.; Wang, S.Y. Antioxidant activity and phenolic compounds in selected herbs. J. Agric. Food Chem. 2001, 49, 5165-5170. [CrossRef]

33. Benzie, I.F.; Strain, J.J. The ferric reducing ability of plasma (FRAP) as a measure of "antioxidant power": The FRAP assay. Anal. Biochem. 1996, 239, 70-76. [CrossRef] [PubMed]

34. Matic, P.; Sabljic, M.; Jakobek, L. Validation of Spectrophotometric Methods for the Determination of Total Polyphenol and Total Flavonoid Content. J. AOAC Int. 2017, 100, 1795-1803. [CrossRef] [PubMed]

35. Slinkard, K.; Singleton, V.L. Total Phenol Analysis: Automation and Comparison with Manual Methods. Am. J. Enol. Vitic. 1977, $28,49$.

36. Seeram, N.P.; Adams, L.S.; Zhang, Y.; Lee, R.; Sand, D.; Scheuller, H.S.; Heber, D. Blackberry, black raspberry, blueberry, cranberry, red raspberry, and strawberry extracts inhibit growth and stimulate apoptosis of human cancer cells in vitro. J. Agric. Food Chem. 2006, 54, 9329-9339. [CrossRef]

37. Kim, E.J.; Lee, Y.-J.; Shin, H.-K.; Park, J.H.Y. Induction of apoptosis by the aqueous extract of Rubus coreanum in HT-29 human colon cancer cells. Nutrition 2005, 21, 1141-1148. [CrossRef] [PubMed]

38. Qu, T.; Wang, E.; Jin, B.; Li, W.; Liu, R.; Zhao, Z.B. 5-Aminosalicylic acid inhibits inflammatory responses by suppressing JNK and p38 activity in murine macrophages. Immunopharmacol. Immunotoxicol. 2017, 39, 45-53. [CrossRef]

39. Li, C.; Feng, J.; Huang, W.Y.; An, X.T. Composition of polyphenols and antioxidant activity of rabbiteye blueberry (Vaccinium ashei) in Nanjing. J. Agric. Food Chem. 2013, 61, 523-531. [CrossRef]

40. Fredes, C.; Montenegro, G.; Zoffoli, J.P.; Gómez, M.; Robert, P. Polyphenol content and antioxidant activity of Maqui (Aristotelia chilensis [Molina] Stuntz) during fruit development and maturation in central Chile. J. Agric. Res. 2012, 72, 582-589. [CrossRef]

41. Hwang, S.J.; Yoon, W.B.; Lee, O.H.; Cha, S.J.; Kim, J.D. Radical-scavenging-linked antioxidant activities of extracts from black chokeberry and blueberry cultivated in Korea. Food Chem. 2014, 146, 71-77. [CrossRef] [PubMed] 
42. Salvia-Trujillo, L.; Morales-de la Pena, M.; Rojas-Grau, A.; Martin-Belloso, O. Changes in water-soluble vitamins and antioxidant capacity of fruit juice-milk beverages as affected by high-intensity pulsed electric fields (HIPEF) or heat during chilled storage. J. Agric. Food Chem. 2011, 59, 10034-10043. [CrossRef] [PubMed]

43. González, B.; Vogel, H.; Razmilic, I.; Wolfram, E. Polyphenol, anthocyanin and antioxidant content in different parts of maqui fruits (Aristotelia chilensis) during ripening and conservation treatments after harvest. Ind. Crops. Prod. 2015, 76, 158-165. [CrossRef]

44. Brauch, J.E.; Buchweitz, M.; Schweiggert, R.M.; Carle, R. Detailed analyses of fresh and dried maqui (Aristotelia chilensis (Mol.) Stuntz) berries and juice. Food Chem. 2016, 190, 308-316. [CrossRef] [PubMed]

45. Reyes-Farias, M.; Vasquez, K.; Ovalle-Marin, A.; Fuentes, F.; Parra, C.; Quitral, V.; Jimenez, P.; Garcia-Diaz, D.F. Chilean native fruit extracts inhibit inflammation linked to the pathogenic interaction between adipocytes and macrophages. J. Med. Food 2015, 18, 601-608. [CrossRef] [PubMed]

46. Hossen, I.; Hua, W.; Ting, L.; Mehmood, A.; Jingyi, S.; Duoxia, X.; Yanping, C.; Hongqing, W.; Zhipeng, G.; Kaiqi, Z.; et al. Phytochemicals and inflammatory bowel disease: A review. Crit. Rev. Food Sci. Nutr. 2019, 1-25. [CrossRef] [PubMed]

47. Moon, H.-D.; Kim, B.-H. Inhibitory effects of Aristotelia chilensis water extract on 2,4-Dinitrochlorobenzene induced atopic-like dermatitis in BALB/c Mice. Asian Pac. J. Allr. Immunol. 2019. [CrossRef]

48. Wijeratne, S.S.; Cuppett, S.L.; Schlegel, V. Hydrogen peroxide induced oxidative stress damage and antioxidant enzyme response in Caco-2 human colon cells. J. Agric. Food Chem. 2005, 53, 8768-8774. [CrossRef]

49. Nunes, C.; Teixeira, N.; Serra, D.; Freitas, V.; Almeida, L.; Laranjinha, J. Red wine polyphenol extract efficiently protects intestinal epithelial cells from inflammation via opposite modulation of JAK/STAT and Nrf2 pathways. Toxicol. Res. 2016, 5, 53-65. [CrossRef]

50. San Hipólito-Luengo, Á.; Alcaide, A.; Ramos-González, M.; Cercas, E.; Vallejo, S.; Romero, A.; Talero, E.; Sánchez-Ferrer, C.F.; Motilva, V.; Peiró, C. Dual Effects of Resveratrol on Cell Death and Proliferation of Colon Cancer Cells. Nutr. Cancer 2017, 69, 1019-1027. [CrossRef]

51. Zengin, G.; Locatelli, M.; Ferrante, C.; Menghini, L.; Orlando, G.; Brunetti, L.; Recinella, L.; Chiavaroli, A.; Leone, S.; Leporini, L.; et al. New pharmacological targets of three Asphodeline species using in vitro and ex vivo models of inflammation and oxidative stress. Int. J. Environ. Health Res. 2019, 29, 520-530. [CrossRef] [PubMed]

52. He, J.; Han, S.; Li, X.-X.; Wang, Q.-Q.; Cui, Y.; Chen, Y.; Gao, H.; Huang, L.; Yang, S. Diethyl Blechnic Exhibits Anti-Inflammatory and Antioxidative Activity via the TLR4/MyD88 Signaling Pathway in LPS-Stimulated RAW264.7 Cells. Molecules 2019, $24,4502$. [CrossRef] [PubMed]

53. Ren, J.; Su, D.; Li, L.; Cai, H.; Zhang, M.; Zhai, J.; Li, M.; Wu, X.; Hu, K. Anti-inflammatory effects of Aureusidin in LPS-stimulated RAW264.7 macrophages via suppressing NF-кB and activating ROS- and MAPKs-dependent Nrf2/HO-1 signaling pathways. Toxicol. Appl. Pharm. 2019, 387, 114846. [CrossRef] 